In C. Murchison (Ed.). Psychologies of 1930. Worcester, Mass: Clark University Press. 1930. Pp. 243-278.

Ladygina-Kots, N. N.. \& Dembovskii. Y. N. The psychology of primates. In M. Cole and I. Maltzman (Eds.), A handbook of contemporary Soviet psychology. New York: Basic Books, 1969. Pp. 41-70

Luria, $A: R$. Speech development and the formation of mental processes. In M. Cole and I. Maltzman (Eds.), $A$ handbook of contemporary Soviet psychology. New York: Basic Books, 1969. Pp. 121-162.

Notterman, J, M. A study of some relations among aperiodic reinforcement. discrimination training, and secondary reinforcement. Journal of Experimental Psychology, 1951
$41,161-169$.

Notterman. 3. M. Behovior: A systematic opproach. New York:

Random House, 1970. Pp. 33-57.

Notterman, J.M Filion, R D. L., \& Mandriota. F. J. Perception of changes in certain exteroceptive stimuli. Science, 1971 , $173,1206-1211$.

Rosenblueth, A. Wiener, N., \& Bigelow, J. Behavior, purpose, and teleology. Philosophy of Science, 1943, 10,18-24.

Watson, J. B. Psychology as a behaviorist views it. Psychological Review, 1913, 20,158-177.

Zaporozhets A V Origin and development of conscious control of movements in mun. Bethesda, Md: National Institutes of Health, 1960. Pp. 1005-1022.

\title{
Choosing a programming system for on-line control of research
}

\author{
WILLIAM SIEGEL \\ University of Western Ontario, London, Ontario, Canada
}

The papers presented at this symposium illustrate very nicely the problem that psychologists using small computers face today: What language should we use for software development? Johnson and Anger (1973) prefer to write programs to run their experiments in Assembly language, while they use either a floating-point interpreter or a FORTRAN compiler for data analysis. Church (1973), together with Howard Dyckman, has developed TIICIE, a special-purpose operating system, which may be used for time-shared control of several concurrent experiments. For data analysis, Church uses a version of FOCAL that he has modified somewhat for his own needs. Snapper (1973), on the other hand, uses his SKED compiler for a variety of applications, including the control of operant experiments, monitoring of bioelectric signals, and data analysis.

To the novice, this plethora of programming systems and lack of standardization may be confusing, but in fact it represents a healthy development in the use of minicomputers in research. Until recently, the user had only one viable option open to him-do everything in Assembly language. There are still a number of individuals who masochistically adhere to this approach, but for someone who prefers to devote his time to psychology rather than to obsolescent computer technology. the advantages of high-level software are obvious.

If written properly, Assembly language programs make efficient use of core memory, but they are wasteful in terms of the programmer's time. The ratio of software/hardware costs is bound to increase dramatically if, as seems inevitable, the price of labor goes up while the price of computers comes down. For example, the staff of the Arthur D. Little Company has projected a cost of about $\$ 400$ for a basic minicomputer in 1980. The price of mass storage is expected to decline even more drastically during this decade as new technologies based on laser. magnetic bubble. or holographic approaches replace magnetic tape and rotating disk systems. These technological advances should have a major effect on the behavior of psychologists who use real-time computers, for, as the average system becomes larger, it will become more feasible to program research using powerful and sophisticated languages. One consequence is that anyone with a modicum of progzamming experience on a large computer will be able to write software quickly and easily on the small-scale system of the future. As laboratory computers become more accessible to the masses, we, the devoted few who dedicated ourselves to the cult of Assembly language, will unfortunately, but inevitably, lose our status as resident gurus.

Fortunately, as this symposium has demonstrated, there is no need to wait until 1980 in order to use high-level languages on small computers; rather the problem is to decide which type of system best fits your current needs. One approach is to use a special-purpose operating system that is tailor-made for your particular research application, and Church's TIIClE system illustrates this approach quite nicely. A number of other operating systems have been written for operant conditioning, psychoacoustic, reaction-time, and signal-averaging applications, etc. If they have been well designed. specialized operating systems can be extremely useful. Because they are restricted to a small number of jobs. they tend to be undemanding of core memory and they may allow fast execution of instructions, a factor which is important in paradigms where critical timing is required.

The main disadvantage of specialized operating systems is that they usually can run only on one computer-that of the individual(s) who wrote the system. That is, they are usually written with one laboratory in mind, and they are therefore tied down to particular configuration of computer. peripherals. interface. and apparatus that happen to be present in that laboratory. This usually means that if you want a special-purpose system to run on lour computer, you will have to write it yourself, a process that may take several years. The resulting development costs may be justifiable if you are sure that you will still be running the same type of experiments in 2 or 3 years. Otherwise. special-purpose systems are probably useful only if you can find one that runs more or less as is on your configuration. 
A second approach is to use a general programming language that makes mathematical operations, program branches, loops, subroutine calls, and text handling easy to accomplish. FORTRAN and BASIC are the most commonly used general languages, although DEC's FOCAL interpreter has made some inroads among owners of that company's machines. Perhaps one could place Snapper's state-oriented language in this category as well, although its scope is somewhat more restricted than that of, say, FORTRAN. Despite the power, flexibility, and ease of use of general-purpose interpreters and compilers, and despite the fact that versions of FORTRAN, FOCAL, and BASIC have been available on small computers for a number of years, these systems have seldom been used for on-line control of experiments. This is due to several built-in limitations of high-level systems: (a) they are wasteful of core memory; (b) timing is slow and often indeterminate, since one does not know how many machine instructions are involved in a particular high-level command; and (c) many high-level systems do not allow the user the flexibility of Assembly language for controlling his experimental apparatus.

The fact that powerful languages may require more than $4 \mathrm{~K}$ of core will pose less of a difficulty as the cost of mass storage decreases. The problem of flexibility has been alleviated to a large degree by the potential for Assembly-language subroutines in the versions of FORTRAN, BASIC, and FOCAL now offered by a number of manufacturers. Braida and his associates at M.I.T. (Braida, Herman, \& Callahan, 1972) have developed a modified version of FOCAL that gets around the problem of sloppy timing in a clever way. With their system, commands may be interpreted well in advance of the time when they are to be executed. In fact, a series of instructions to, say, control an oscillator's frequency and gate it on and off at appropriate intervals may be stored in a command buffer. The execution of these compiled commands may then be synchronized with the ticking of a hardware clock. In this way, very precise timing is achieved.

While all three of the difficulties associated with general-purpose programming languages-slow, imprecise timing of commands, inefficient use of core, and lack of flexibility-are potentially soluble, it is unlikely that a single system will ever be developed that is optimal for every user. The solution is to use whatever system is most appropriate for the task at hand, rather than fixating upon either straight Assembly-language programming or upon some particular high-level language. For example, in several of the papers presented in this symposium, the use of FORTRAN and FOCAL is restricted to the data-analysis stage of the experiment when critical timing is not required.

My preference is to do everything possible in an interactive, high-level language, resorting to Assembly language only when necessary. Typically, we use FOCAL programs to input parameters for an experimental session and to compute all of the information about that session that may be specified in advance. A chained Assembly-language program then runs the trials and collects the Ss' responses. Then a FOCAL program is called from tape or disk for data analysis. We found it necessary to develop software for chaining of FOCAL and Assembly-language programs and to allow the two types of programs to communicate through common data files (Siegel, 1972; Siegel \& Whittle, 1972; Whittle \& Siegel, 1972).

Ideally, then, one would like to be able to conveniently interleave programs written with whatever system is most convenient for the task at hand. At the moment, this is impossible, but not because of any logical incompatibility of the various high-level and low-level systems. Rather, the programmers who have developed systems software have made arbitrary decisions about input/output operations and file structures that make it difficult to interleave programs written in different languages. For example, Johnson and Anger coded their data in ASCII format so that it would be intelligible to a FORTRAN compiler, while Church used a binary format that was compatible with FOCAL-12. Obviously, it would be easier for us to borrow our colleagues' operating systems and programs if all of the irrelevant details were standardized, and if they were thus compatible with our existing sof tware.

The possibility of software compatibility has been greatly enhanced by the recent availability of sophisticated programming systems for small computers, such as DEC's OS/8. The latter consists of a monitor under which a variety of systems software, including assemblers, compilers, editors, and loading routines, are available. The $\mathrm{OS} / 8$ system employs a modular programming technique so that, if a new peripheral is added to the system, one need only write a short $\mathrm{I} / \mathrm{O}$ handler for it rather than making extensive modifications of the system. A common file structure and data format are employed for the various programming languages running under OS/8.

By writing our software so that it runs under a general programming system, by emulating the modular programming techniques now being adopted by the manufacturers, by incorporating their standard modules into our own programs, and by using a standard file structure, we will have come a long way toward easing the burden of programming small computers. I look forward to the day when FORTRAN, BASIC, FOCAL, SKED, TIICIE, and a variety of useful software systems will all be available under the same monitor and when programs written in each of these languages will be able to access data in common files. Then we will be in the luxurious position of being able to choose, quickly and easily, the programming language that is best suited for the task at hand.

\section{REFERENCES}

Braida, L. D., Herman, P. W., \& Callahan, D. J. PSYCBL-a 
FOCAL based system for real time control of experiments. Proceedings of the Spring DECUS Sy mposium, 1972, 207.

Church, R. M. Seven types of data from computer-controlled experiments. Behavior Research Methods \& Instrumentation, $1973,5,122-124$

Johnson, B. L., \& Anger, W. K. Time discrimination training of laboratory animals using a PDP-8 computer. Behavior Research Methods \& Instrumentation, 1973, 5, 117-121.

Siegel, W. Combining FOCAL and Assembly language. Behavior
Research Methods \& Instrumentation, 1972, 4, 105-106.

Siegel, W. \& Whittle, $K$. Using FOCAL in research. In Computers in the psychology laboratory. Vol. II. Maynard, Mass: Digital Equipment Corp., 1972.

Snapper, A. G. Use of a notation system for digital control and recording. Behavior Research Methods \& Instrumentation. $1973,5,124-129$.

Whittle, K., \& Siegel, W. FOCAL-RT user's guide. DECUS Program Library, No $12-80$, June 1972. 